\title{
Effects of intralesional platelet-rich plasma in the patients with lateral epicondylitis of elbow
}

\author{
Mohammad Tariqul Islam, M. A. Shakoor, Afsana Mahjabin and Md. Ali Emran
}

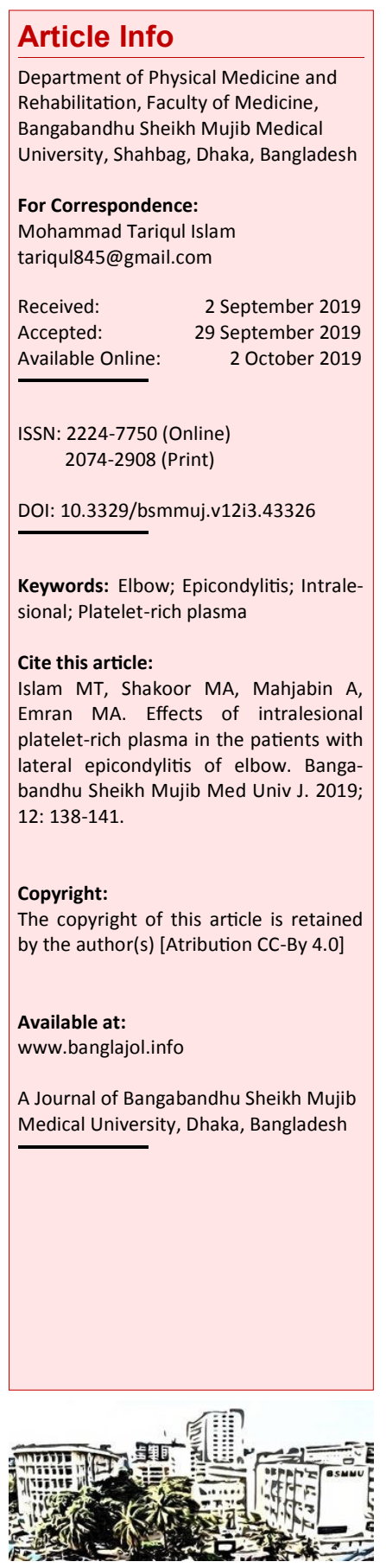

\begin{abstract}
Lateral epicondylitis (tennis elbow) is a major cause of musculoskeletal pain involving common extensor origin of the forearm. This study was done to determine the effects of platelet-rich plasma on 15 patients with lateral epicondylitis. Selected patients were given intralesional platelet-rich plasma injection, activity of daily living instructions and paracetamol. Patients were assessed every 14 days interval by visual analogue scale, and the patient rated tennis elbow evaluation. Treatment response according to visual analogue scale and patient rated tennis elbow evaluation tool, the difference of improvement was found in respect to time, from pretreatment W1 (just before $1^{\text {st }}$ Intervention) score to W11 score in every alternate week $(\mathrm{p}<0.005)$. This indicates that intralesional platelet-rich plasma is effective in patients with lateral epicondylitis of elbow.
\end{abstract}

\section{Introduction}

One of the most common causes of musculoskeletal pain is the lateral epicondylitis, which involves common extensor origin of the forearm. Its incidence and prevalence are 1-3\% and $10 \%$ respectively on general population among working people aged over 45 years old with high-risk jobs (strenuous for the arms).1,2 It arises due to repetitive manual work involving overexertion of wrist and finger extensors and imparts significant disability in terms of quality of daily life activities. Clinically, it expresses both direct and indirect tenderness at the lateral epicondyle. 1,2 Although the diagnosis of lateral epicondylitis is quite straight forward, the optimal management strategy has no consensus. $\underline{3}$ However, non-surgical treatment includes rest, physiotherapy, epicondylar counterforce braces, non-steroidal anti-inflammatory drugs, corticosteroid injection, autologous blood injection, platelet-rich plasma injection, percutaneous radiofrequency thermal treatment, extracorporal shock wave therapy, use of low-level laser therapy, acupuncture and botulinum toxin A injection. $\underline{4-7}$

A systematic review and meta-analysis showed the effect of a range of physical interventions like non-electrotherapeutic interventions such as exercise, manipulation technique, orthotics and taping, acupuncture and electrotherapeutic interventions such as laser, ultrasonic therapy with phonophorosis, electromagnetic field therapy, on various outcomes for lateral epicondylitis and failed to explicate any long term favorable effects over that of a placebo group. 8 Local steroid injection has been proven to provide consistent and predictable shortterm pain relief but no action on reparative process. 2 New treatment options include local injection of platelet-rich plasma, autologous blood, prolotherapy and extracorporeal shock wave therapy.10-12 Platelet-rich plasma is a concentrate of platelets derived from the patient's own blood. Platelets in platelet-rich plasma contain numerous growth factors and build-up reparative processes.

In lateral epicondylitis, there may be complex changes in the tendon in addition to an inflammatory process. Therefore, platelet-rich plasma owing to its high content of various growth factors may be more efficacious as a healing agent. $13-15$ Treatment of patients with chronic lateral epicondylitis with platelet-rich plasma not only reduces pain but also increases function significantly, exceeding the effect of corticosteroid injection even after a follow-up of 2 years. 16 In another study, an injection of platelet-rich plasma improves the pain and function in patients suffering from lateral epicondylitis where conservative management has failed. 17 In another study, the effectiveness of a single injection of platelet-rich plasma, after 3 months, showed that the pain and disability of lateral epicondylitis was not adequately reduced. 18 So, infiltration with autologous blood, buffered platelet-rich plasma or autologous growth factors seem promising, but 
Table I

Baseline characteristics of patients and analysis of pain

\begin{tabular}{|c|c|c|}
\hline \multicolumn{2}{|l|}{ Attributes } & \\
\hline \multicolumn{2}{|l|}{ Age (year) } & $42.5 \pm 8.3$ \\
\hline \multicolumn{2}{|l|}{ Height (cm) } & $158.5 \pm 6.0$ \\
\hline \multicolumn{2}{|l|}{ Weight (kg) } & $57.8 \pm 7.7$ \\
\hline \multicolumn{2}{|c|}{ Duration of elbow pain (month) } & $8.0 \pm 5.3$ \\
\hline \multicolumn{2}{|l|}{ Analysis of pain } & Frequency \\
\hline \multirow[t]{2}{*}{ Character of pain } & Constant & 4 \\
\hline & Intermittent & 11 \\
\hline \multirow[t]{3}{*}{ Aggravating Factors } & Heavy weight lifting & 3 \\
\hline & Twisting movement & 1 \\
\hline & Repeated stress & 11 \\
\hline \multirow[t]{2}{*}{ Relieving factors } & Rest & 14 \\
\hline & Taking NSAIDS & 1 \\
\hline
\end{tabular}

require further investigation. $\underline{19}$

Due to angiogenesis, increase growth factor expression and cell proliferation, platelet-rich plasma therapy is used to increase the reparative process and tensile strength in chronic tendinopathies.20 Some studies showed that platelet-rich plasma therapy decreases pain and increases functional improvement 16,17 whereas other studies showed inconclusive results. $18,15,21-22$ Hence, this study was conducted to find out the efficacy of platelet-rich plasma in terms of pain relief and functional improvement.

\section{Materials and Methods}

This prospective experimental study was conducted from March 2017 to February 2018 to determine the effects of platelet-rich plasma on the patients with lateral epicondylitis.

Patients with lateral epicondylitis, age 21 to 60 years and suffering from more than one month, irrespective of sexes were included whereas patients with history of arthritis, trauma, severe anemia, active systemic infection, bleeding disorder were excluded from the study. Fifteen patients were selected for this study. Intralesional platelet-rich plasma injection, activity of daily living instructions and paracetamol were given to each patient. About 3-4 $\mathrm{mL}$ of platelet-rich plasma was injected into the lateral epicondylar region and the patient was advised to take paracetamol $500 \mathrm{mg}$ twice daily during the entire treatment period. Regarding activity of daily instruction of patient was advised not to do any twisting activities, weight lifting, sweeping, cloth squeezing, etc.
Patients were assessed every 14 days interval. Intralesional platelet-rich plasma was given in first (W1) and forth (W7) treatment visits. Each visit patients were assessed by visual analogue scale (VAS) and the patient rated tennis elbow evaluation (PRTEE) tools. Statistical analysis was performed by Statistical Packages for Social Sciences (SPSS-21). P value $<0.05$ was considered as statistically significant.

Blood sample collection and platelet-rich plasma preparation

Selected patients were sent to Transfusion Medicine Department. There about $15-20 \mathrm{~mL}$ blood was collected to prepare platelet-rich plasma. Blood was collected in sterile procedure (venepuncture technique almost identical to having a standard blood collection for pathology testing) and allowed it to spin in a centrifuge machine about 3,200 rpm for 15 min. Then, the blood was separated into its various constituents: red blood cells on the bottom, plasma on the top, and platelets in the middle. On the top of the red blood cell layer, there was buffy coat. Then, about 3-4 mL of buffy coat was extracted and which was platelet-rich plasma. This platelet-rich plasma was used in this study. The entire process took less than $30 \mathrm{~min}$.

\section{Results}

Baseline characteristic of the patients and analysis of the pain were described in Table I.

Treatment response in relation to weeks according to VAS

There was significant improvement. In respect to time, improvement was started to occur in pretreatment W1 (just before $1^{\text {st }}$ Intervention) score vs W3 score which was $6.2 \pm 2.1$ vs $4.0 \pm 1.6$ respectively $(p=0.000)$. Then, $\mathrm{W} 3$ vs $\mathrm{W} 5$ score was $4.0 \pm 1.6$ vs $3.0 \pm 1.3$ respectively $(\mathrm{p}=0.001)$. Then, W5 vs W7 (just before $2^{\text {nd }}$ Intervention) score $3.0 \pm$ 1.3 vs $2.7 \pm 1.0$ respectively ( $p=0.096$ ). Then, $W 7$ (just before $2^{\text {nd }}$ Intervention) vs W9 score $2.7 \pm 1.0$ vs 1.4 \pm 0.6 respectively $(\mathrm{p}=0.000)$. Then, $\mathrm{W} 9$ vs $\mathrm{W} 11$ score was $1.4 \pm 0.6$ vs $0.5 \pm 0.5$ respectively $(p=0.000)$. This indicates that intralesional platelet-rich plasma was effective in lateral epicondylitis of elbow (Table II).

Treatment response in relation to weeks according to PRTEE

There was also significant improvement. In respect to time, improvement was started to occur in pretreatment W1 (just before $1^{\text {st }}$ Intervention) vs W3 score which was $52.2 \pm 13.3$ vs $42.4 \pm 12.9$ respectively $(\mathrm{p}=0.000)$. Then $\mathrm{W} 3$ vs $\mathrm{W} 5$ score was $42.4 \pm 12.9$ vs $34.2 \pm 11.5$ respectively $(p=0.000)$. Then, W5 vs W7 (just before $2^{\text {nd }}$ Intervention) score was $34.2 \pm 11.5$ vs $24.1 \pm 7.8$ respectively $(p=0.000)$. 
Table II

Treatment response in relation to weeks according to VAS and PRTEE $(n=15)$

\begin{tabular}{|c|c|c|c|c|c|c|}
\hline $\begin{array}{l}\text { Assessment } \\
\text { Tools }\end{array}$ & $\begin{array}{l}\text { Time-point } \\
\text { score }\end{array}$ & $\begin{array}{c}\text { W1 (1st Intervention) } \\
\text { vs W3 }\end{array}$ & W3 vs W5 & $\begin{array}{l}\text { W5 vs W7 (2nd } \\
\text { Intervention) }\end{array}$ & $\begin{array}{l}\text { W7 (2nd Interven- } \\
\text { tion) vs W9 }\end{array}$ & W9 vs W11 \\
\hline \multirow{4}{*}{$\begin{array}{l}\text { Visual ana- } \\
\text { logue scale }\end{array}$} & Mean $\pm S D$ & $6.2 \pm 2.0$ & $4.0 \pm 1.6$ & $3.0 \pm 1.3$ & $2.7 \pm 1.0$ & $1.4 \pm 0.6$ \\
\hline & & vs & vs & vs & vs & vs \\
\hline & & $4.0 \pm 1.6$ & $3.0 \pm 1.3$ & $2.7 \pm 1.0$ & $1.4 \pm 0.6$ & $0.5 \pm 0.5$ \\
\hline & p value & 0.000 & 0.001 & 0.096 & 0.000 & 0.000 \\
\hline \multirow{4}{*}{$\begin{array}{l}\text { Patient rated } \\
\text { tennis elbow } \\
\text { evaluation }\end{array}$} & Mean \pm SD & $52.2 \pm 13.3$ & $42.4 \pm 12.9$ & $34.2 \pm 11.5$ & $24.1 \pm 7.8$ & $12.9 \pm 5.5$ \\
\hline & & vs & vs & vs & vs & vs \\
\hline & & $42.4 \pm 12.9$ & $34.2 \pm 11.5$ & $24.1 \pm 7.8$ & $12.9 \pm 5.5$ & $4.2 \pm 3.10$ \\
\hline & $p$ value & 0.000 & 0.000 & 0.000 & 0.000 & 0.000 \\
\hline
\end{tabular}

Then W7 (just before $2^{\text {nd }}$ Intervention) vs W9 score $24.1 \pm 7.8$ vs $12.9 \pm 5.5$ respectively $(\mathrm{p}=0.000)$. Then W9 vs W11 score was $12.9 \pm 5.5$ vs $4.2 \pm 3.1$ respectively $(p=0.000)$. This indicates that intralesional platelet-rich plasma was effective in lateral epicondylitis of elbow (Table II).

\section{Discussion}

The present study showed that the subjective and objective measures of pain as well as functional parameters were improved following administration of intralesional platelet-rich plasma.

The difference of improvement was found in respect to time, from pretreatment W1 (just before 1st intervention) to W11 score in every alternate week which was statistically significant. Patient's pain was decreased due to subsiding inflammatory process and healing of the diseased tendon by various growth factors secreted from platelets. $\frac{13-15}{1 n}$ a similar study, it was found intralesional platelet-rich plasma showed significant improvement in pain scores using visual analogue scale than placebo at 12 and 24 weeks ( $p$ value <0.001)..$\underline{23}$ Therefore, platelet-rich plasma was effective as it reduces subjective measures of pain.

In the present study, the difference of improvement was found in respect to time, from pretreatment W1 (just before 1st Intervention) to W11 score in every alternate week. Patient's pain and functional parameters were improved due to subsiding inflammation, tissue regeneration and increase tensile strength. $13-15,20$

In another study, it was found that intalesional platelet -rich plasma injection showed significant pain relief and gain in function as well as quality of life 6 months after intervention by using patient rated tennis elbow evaluation tool, even with a single platelet-rich plasma injection. Where they showed that the mean baseline to 6-month follow-up scores of the patient rated tennis elbow evaluation questionnaires improved significantly from 54.0 to 63.0 .25 So that the mean platelet-rich plasma was effective as it reduces pain and improves patient's functional improvement.
Hence, treatment response according to visual analogue scale and patient rated tennis elbow evaluation, the difference of improvement was found in respect to time, from pretreatment W1 (just before 1st Intervention) to W11 score in every alternate week, which was supported by other studies. $.5-28$

\section{Conclusion}

Intralesional platelet-rich plasma showed significant improvement in patients with lateral epicondylitis of elbow.

\section{Ethical Issue}

The protocol was approved by the Institutional Review Board of the University (BSMMU/2016/2380).

\section{Conflict of Interest}

Authors declare no conflict of interest.

\section{Acknowledgement}

We are grateful to the Department of Transfusion Medicine for their kind co-operation.

\section{References}

1. Harrington JM, Carter JT, Birrell L, Gompertz D. Surveillance case definitions for work related upper limb pain syndromes. Occup Environ Med. 1998; 55: 264-71.

2. Kivi P. The etiology and conservative treatment of humeral epicondylitis. Sacnd J Rehabil Med. 1983; 15: 37-41.

3. Labelle H, Guibert R, Joncas J, Newman N, Fallaha M, Rivard CH. Lack of scientific evidence 
for the treatment of lateral epicondylitis of the elbow: An attempted meta-analysis. J Bone Joint Surg. 1992; 74: 646-51.

4. Vaquero-Picado A, Barco R, Antuña SA. Lateral epicondylitis of the elbow. EFORT Open Rev. 2016; 1: 391-97.

5. Cohen M, da Rocha Motta Filho G. Lateral epicondylitis of the elbow. Rev Bras Ortop. 2012; 47: 414-20.

6. Sims SE, Miller K, Elfar JC, Hammert WC. Nonsurgical treatment of lateral epicondylitis: A systematic review of randomized controlled trials. Hand (NY). 2014; 9: 419-46.

7. Khandaker MN, Islam S, Emran MA, Islam J, Ahmed SM, Khan MM, Salek AKM. The effect of stretching exercise in the management of lateral epicondylitis. Bangladesh Med J. 2014; 43: 61-66.

8. Bisset L, Paungmali A, Vicenzino B, Beller E, Herbert R. A systematic review and meta-analysis of clinical trials on physical interventions for lateral epicondylalgia. Br J Sports Med. 2005; 39: 411-22.

9. Tonks JH, Pai SK, Murali SR. Steroid injection therapy is the best conservative treatment for lateral epicondylitis: A prospective randomised controlled trial. Int J Clin Pract. 2007; 61: 240-46.

10. Smith MA, Smith WT. Emerging techniques in orthopaedics: Platelet-rich plasma. Orthop Nurs. 2011; 30: 260-63.

11. Behrens SB, Deren ME, Matson AP, Bruce B, Green A. A review of modern management of lateral epicondylitis. Phys Sportsmed. 2012; 40: 3440 .

12. Childress MA, Beutler A. Management of chronic tendon injuries. Am Fam Physician. 2013; 87: $486-$ 90 .

13. Mishra A, Pavelko T. Treatment of chronic elbow tendinosis with buffered platelet-rich plasma. Am J Sports Med. 2006; 34: 1774-78.

14. Mishra A, Collado H, Fredericson M. Platelet-rich plasma compared with corticosteroid injection for chronic lateral elbow tendinosis. PMR. 2009; 1: 366 -70 .

15. Raeissadat SA, Rayegani SM, Hassanabadi H, Rahimi R, Sedighipour L, Rostami K. Is plateletrich plasma superior to whole blood in the management of chronic tennis elbow?: One year randomized clinical trial. BMC Sports Sci Med Rehabil. 2014; 6: 12.

16. Gosens T, Peerbooms JC, van Laar W, den Oudsten BL. Ongoing positive effect of plateletrich plasma versus corticosteroid injection in lateral epicondylitis: A double-blind randomized controlled trial with 2-year follow-up. Am J Sports Med. 2011; 39: 1200-08.

17. Brkljac M, Kumar S, Kalloo D, Hirehal K. The effect of platelet-rich plasma injection on lateral epicondylitis following failed conservative management. J Orthop. 2015; 12: S166-70.

18. Shiple BJ. How effective are injection treatments for lateral epicondylitis? Clin J Sport Med. 2013; 23: 502-03.

19. Palacio EP, Schiavetti RR, Kanematsu M, Ikeda TM, Mizobuchi RR, Galbiatti JA. Effects of platelet -rich plasma on lateral epicondylitis of the elbow: Prospective randomized controlled trial. Rev Bras Ortop. 2016; 51: 90-95

20. Yadav R, Kothari SY, Borah D. Comparison of local injection of platelet-rich plasma and corticosteroids in the treatment of lateral epicondylitis of humerus. J Clin Diagn Res. 2015; 9: RC05-07.

21. Mishra A, Pavelko T. Treatment of chronic elbow tendinosis with buffered platelet-rich plasma. Am J Sports Med. 2006; 34: 1774-78.

22. Mishra A, Collado H, Fredericson M. Platelet-rich plasma compared with corticosteroid injection for chronic lateral elbow tendinosis. PMR. 2009; 1: 366 -70 .

23. Seetharamaiah VB, Gantaguru A, Basavarajanna S. A comparative study to evaluate the efficacy of platelet-rich plasma and triamcinolone to treat tennis elbow. Indian J Orthop. 2017; 51: 304-11.

24. Glanzmann MC, Audigé L. Platelet-rich plasma for chronic lateral epicondylitis: Is one injection sufficient? Arch Orthop Trauma Surg. 2015; 135: 1637-45.

25. Brkljac M, Kumar S, Kalloo D, Hirehal K. The effect of platelet-rich plasma injection on lateral epicondylitis following failed conservative management. J Orthop. 2015; 12: S166-70.

26. Varshney A, Maheshwari R, Juyal A, Agrawal A, Hayer P. Autologous platelet-rich plasma versus corticosteroid in the management of elbow epicondylitis: A randomized study. Int J Appl Basic Med Res. 2017; 7: 125-28.

27. Arirachakaran A, Sukthuayat A, Sisayanarane $\mathrm{T}$, Laoratanavoraphong S, Kanchanatawan W, Kongtharvonskul J. Platelet-rich plasma versus autologous blood versus steroid injection in lateral epicondylitis: Systematic review and network meta-analysis. J Orthop Traumatol. 2016; 17: 10112.

28. Ben-Nafa W, Munro W. The effect of corticosteroid versus platelet-rich plasma injection therapies for the management of lateral epicondylitis: A systematic review. SICOT J. 2018; 4: 11. 